\title{
HUBUNGAN JANGKA PENDEK DAN JANGKA PANJANG DI ANTARA FDI, EKSPOR DAN PDB
}

\author{
Hary Saputra Sundoro \\ Fakultas Ilmu Sosial dan Humaniora Universitas Bunda Mulia, Tangerang, \\ Indonesia \\ Email: sundorohs@gmail.com, No. Tlp: 081316526365
}

\begin{abstract}
A global trade war is expected to impact the economy of every country. The purpose is to examine relationship between FDI, Exports and GDP during global trade war. It is hoped that the stakeholders, especially the government, can take the necessary actions. The research method used is VECM with quarterly analysis starting from 2010 to 2019. The result shows that there is a positive relationship between Exports and GDP in the short and long term. During the era of the global trade war, foreign investment will be more horizontal in nature with the aim of market sharing. Thus, there is a negative relationship between FDI with exports and GDP in Indonesia. The implication of this research is that the government must make policies that can attract FDI more vertically. Therefore, FDI will be prioritized for the exploration of inputs where output will be exported outward and GDP will also rise
\end{abstract}

Keywords: Exports; FDI; GDP; Trade War; VECM.

\begin{abstract}
ABSTRAK
Munculnya perang dagang global dapat memberikan dampak bagi perekonomian setiap negara. Tujuan penelitian ini membahas bagaimana hubungan di antara PDB, ekspor dan FDI pada era perang dagang global. Dengan mengetahui bagaimana pola hubungan mereka, maka diharapkan para pihak terkait terutama Pemerintah dapat mengambil tindakan yang diperlukan. Metode penelitian yang digunakan yaitu VECM dengan analisis secara triwulanan mulai dari tahun 2010 sampai dengan tahun 2019. Hasil penelitian ini adalah adanya hubungan positif di antara Ekspor dan PDB dalam jangka pendek maupun jangka panjang. Selama era perang dagang global, investasi asing akan lebih bersifat horizontal dengan tujuan market sharing. Dengan demikian, adanya hubungan negatif di antara FDI dengan Ekspor maupun PDB di Indonesia. Implikasi penelitian ini adalah Pemerintah harus membuat kebijakan yang dapat menarik FDI lebih bersifat vertikal. Oleh karena itu, FDI nantinya akan lebih diutamakan untuk eksplorasi input yang nantinya output akan diekspor ke luar dan PDB pun akan turut naik.
\end{abstract}

Kata Kunci: Ekspor; FDI; PDB; Perang Dagang; VECM. 


\section{PENDAHULUAN}

Perang dagang di antara Amerika Serikat (AS) dan Cina dimulai pada awal tahun 2018 dengan Presiden AS yang sedang menjabat waktu itu menaikan bea masuk untuk barang impor dari Cina (Carvalho et al., 2019). Dengan adanya kenaikan bea masuk untuk barang-barang Cina ke AS, maka Pemerintah Cina memberikan tindakan balasan dengan menaikan bea masuk terhadap 128 produk AS. Tindakan saling menaikan bea masuk untuk masing-masing negara tersebut secara tidak langsung dapat menyebabkan perang dagang di antara kedua negara tersebut.

Perang dagang yang terjadi di antara AS dengan Cina, antara Uni Eropa dengan Britania Raya dan bahkan perang dagang di antara negara-negara lainnya dapat memberikan dampak terhadap negara-negara di kawasan atau bahkan secara global. Dampak utama yang paling dicemaskan dari terjadinya perang dagang yaitu resesi global (Steinbock, 2018). Perang dagang antara negara satu dengan negara lain dapat membuat kinerja ekspor-impor pada negara-negara lainnya akan semakin lesu. Kinerja ekspor-impor yang semakin lesu pada suatu negara dapat menyebabkan kegiatan produksi dan konsumsi domestik di negara tersebut juga turut terpengaruh.

Tabel 1.

Perdagangan Republik Indonesia (RI) dengan Cina

\begin{tabular}{cccc}
\hline \multicolumn{4}{c}{ Perdagangan RI dengan Cina (US\$ Milyar) } \\
\hline Periode & Ekspor & Impor & Neraca \\
2015 & 15,04 & 29,41 & $-14,36$ \\
2016 & 16,79 & 30,80 & $-14,00$ \\
\hline
\end{tabular}




\begin{tabular}{|c|c|c|c|}
\hline \multicolumn{4}{|c|}{ Perdagangan RI dengan Cina (US\$ Milyar) } \\
\hline Periode & Ekspor & Impor & Neraca \\
\hline 2017 & 23,08 & 35,76 & $-12,68$ \\
\hline 2018 (I) & 10,24 & 18,36 & $-8,12$ \\
\hline
\end{tabular}

Sumber: BPS, data diolah 2020

Tabel 2.

Perdagangan Republik Indonesia (RI) dengan AS

\begin{tabular}{cccc}
\hline \multicolumn{4}{c}{ Perdagangan RI dengan AS (US\$ Milyar) } \\
\hline Periode & Ekspor & Impor & Neraca \\
2015 & 16,24 & 7,59 & 8,64 \\
2016 & 16,14 & 7,29 & 8,84 \\
2017 & 17,79 & 8,12 & 9,67 \\
$2018(\mathrm{I})$ & 7,42 & 3,86 & 3,56 \\
\hline
\end{tabular}

Sumber: BPS, data diolah 2020

Berdasarkan Tabel 1 dapat diketahui bahwa nilai ekspor-impor Indonesia dengan Cina mengalami penurunan yang sangat signifikan. Perdagangan di antara Indonesia dengan AS berdasarkan Tabel 2 memang mengalami surplus sebesar 8,64 Milyar US\$ di tahun 2015; 8,84 Milyar US\$ di tahun 2016; dan 9,67 Milyar US\$ di tahun 2017. Namun bagaimanapun juga, secara keseluruhan perdagangan dengan kedua negara besar tersebut Indonesia mengalami penurunan nilai eksporimpornya dengan kisaran -5,78 Milyar US\$ di tahun 2015; -5,16 Milyar US\$ di tahun 2016, dan -3 Milyar US\$ di tahun 2017. Penurunan kegiatan ekspor dapat menyebabkan kegiatan produksi domestik di Indonesia juga akan mengalami 
penurunan. Akhirnya pertumbuhan ekonomi Indonesia yang tercermin dari PDBnya juga akan turut turun. Beberapa temuan sebelumnya juga menyatakan bahwa ketika adanya penurunan kegiatan ekspor di suatu negara, maka PDB negara tersebut juga akan mengalami penurunan (Vardari, 2015; Petrevski \& Jovanovski, 2017 mau pun Raza \& Ying, 2017).

Untuk mengantisipasi penurunan pertumbuhan ekonomi maka setiap Pemerintah harus dapat meningkatkan kegiatan investasinya dan salah satu investasi yang dapat dilakukan dengan menarik investasi asing (Eryigit, 2012). Investasi asing (Foreign Direct Investment - FDI) dapat dilakukan ketika investasi domestik sedang mengalami perlambatan. Perang dagang global dapat membuat kegiatan produksi domestik menurun karena adanya tingkat ekspor yang sedang turun pula. Oleh karena itu dibutuhkannya investasi asing dari luar negeri yang tetap dapat membuat stimulus perekonomian suatu negara walaupun tingkat ekspor sedang turun.

Vardari (2015) melakukan penelitiannya di Kosovo dengan data mulai dari tahun 2004 sampai dengan tahun 2014. Hasil penelitiannya adalah dalam jangka panjang adanya hubungan yang positif di antara tingkat ekspor dengan pertumbuhan ekonomi di Kosovo. Hasil penelitian lain yang dilakukan oleh Raza dan Ying (2017) menemukan bahwa dalam jangka pendek tidak adanya keterkaitan di antara tingkat ekspor dengan PDB. Sebaliknya masih menurut penelitian tersebut, adanya hubungan secara positif di antara tingkat ekspor dengan PDB di Pakistan dalam jangka panjang. Berdasarkan hasil-hasil penelitian tersebut adanya kemungkinan besar di jangka panjang ketika tingkat ekspor 
sedang turun, maka PDB suatu negara juga turun ataupun sebaliknya. Dalam jangka pendek terdapat kemungkinan tidak adanya hubungan di antara ekspor dengan PDB karena kedua variabel tersebut lebih merespon terhadap kebijakan politik Pemerintah di negara yang bersangkutan.

Beberapa penelitian terdahulu pernah meneliti hubungan antara FDI dengan PDB di beberapa negara Asia seperti Thailand (Mandal, 2012), Indonesia (Suyanto et al., 2012) dan Pakistan (Rahman \& Shahbaz, 2013). Oladipo (2013) mengukur hubungan antara FDI dengan pertumbuhan ekonomi di 16 negara pada kawasan Amerika dan Kepulauan Karibian. Hasilnya adalah sebanyak 13 negara yang menjadi sampelnya menunjukkan bahwa adanya hubungan di antara FDI dengan PDB. Namun sebaliknya, hasil penelitian yang dilakukan oleh Tekin (2012) pada 18 negara maju menemukan bahwa hanya ada 4 negara sampelnya yang menunjukkan adanya hubungan di antara FDI dengan PDB. Hasil-hasil penelitian tersebut dapat dikatakan bahwa adanya kemungkinan besar untuk negara-negara berkembang memerlukan investasi. Oleh karena itu, keterkaitan di antara FDI dengan PDB pada negara-negara berkembang dapat berpotensi besar.

Hubungan dalam jangka pendek maupun hubungan jangka panjang di antara FDI, tingkat ekspor dan PDB yang terjadi Indonesia tentunya dapat berbeda atau pun sama dalam kondisi perang dagang global ini. Oleh karena itu, diperlukannya sebuah penelitian yang membahas bagaimana hubungan ketiga variabel tersebut baik dalam jangka pendek mau pun dalam jangka panjang. Kontribusi yang diharapkan dapat diberikan oleh penelitian ini adalah para pihak terkait terutama Pemerintah dapat mengambil tindakan yang diperlukan seperti 
kebijakan yang terkait dengan FDI, tingkat ekspor dan PDB. Jika hubungan ketiganya positif dalam jangka pendek maupun jangka panjang, maka Pemerintah dapat mengambil kebijakan untuk meningkatkan FDI sehingga ekspor dan PDB juga turut naik di tengah perang dagan global seperti sekarang. Namun sebaliknya jika ternyata adanya hubungan yang sifatnya negatif, maka Pemerintah dapat berupaya mengambil kebijakan lainnya agar keadaan ekonomi tetap terjaga di tengah perang dagang global ini. Penelitian tentang hubungan di antara FDI, tingkat ekspor dan PDB telah banyak yang melakukannya. Namun lain hal jika latar belakang penelitian dilakukan ketika munculnya kondisi perang dagang global dan dilakukan di negara berkembang seperti di Indonesia, maka masih jarang yang melakukannya.

\section{METODE PENELITIAN}

Penelitian ini dilakukan untuk meramalkan hubungan di antara FDI, tingkat ekspor dan PDB. Dengan demikian, penelitian ini tidak menjelaskan pengkategorian yang masuk ke dalam kategori variabel bebas atau pun variabel terikat karena penelitian ini lebih menjelaskan hubungan di antara variabelvariabel yang diteliti. Hubungan dari semua variabel yang diteliti akan saling timbal balik.

Ada pun jenis data yang digunakan pada penelitian ini adalah data sekunder berupa data yang sudah dipublikasikan dan dapat diakses secara umum. Penelitian ini akan menggunakan analisis Impulse Response Function dengan metode VECM. Ketika sebuah penelitian ingin mengetahui hubungan di antara 
variabel dalam jangka pendek maupun jangka panjang, maka metode VECM yang paling tepat. Data penelitian ini dalam bentuk time series (kurun waktu) secara kuartalan. Periode penelitian dimulai pada awal tahun 2010 dimana adanya restriksi terhadap produk makanan genetik dari Kanada ke Eropa dengan cara mengenakan tarif yang tinggi (Viju et al., 2011). Kemudian, periode penelitian ini akan diakhiri pada akhir tahun 2019. Data pada penelitian ini merupakan data sekunder yang berarti semua data pada semua variabel di penelitian ini dapat dikumpulkan dari beberapa sumber. Tabel 3 dapat menunjukkan sumber-sumber data untuk masing-masing variabel. Seperti terlihat di Tabel 3 bahwa satuan ukur pada data di semua variabel penelitian ini ada yang dalam bentuk nominal dan persentase. PDB dalam bentuk persentase, tetapi FDI dan tingkat ekspor dalam bentuk nominal. Oleh karena itu, data pada FDI dan tingkat ekspor akan diubah ke dalam persentase mengikuti data pada PDB.

Tabel 3.

Jenis Data, Simbol, Satuan, dan Sumber Data

\begin{tabular}{lllll}
\hline No. & Jenis Variabel & Simbol & Satuan & Sumber Data \\
\hline 1. & Produk Domestik Bruto & PDB & Persentase & BPS \\
2. & Foreign Direct Investment & FDI & Nominal & BKPM \\
3. & Tingkat Ekspor & EXP & Nominal & CEIC \\
\hline
\end{tabular}

Sumber: Gabungan beberapa data, 2020

Penelitian ini menggunakan tiga variabel yang dapat dijabarkan sebagai berikut: Produk Domestik Bruto (PDB) dapat mengindikasikan pertumbuhan ekonomi di suatu negara. Dengan demikian, proksi variabel PDB pada penelitian ini dapat diukur dengan melihat pertumbuhannya. Data pertumbuhan PDB dapat 
diambil secara langsung pada website Badan Pusat Statistik (BPS) secara triwulanan.

Foreign Direct Investment (FDI) merupakan nilai investasi dari pihak asing yang masuk ke dalam suatu negara. Dengan demikian, proksi FDI masih dalam bentuk nominal. Data nominal FDI dapat diambil langsung pada website Badan Koodinasi Penanaman Modal (BKPM). Data yang diperoleh dalam bentuk nominal pada satuan Milyar US Dollar. Untuk menyamakan proksi dalam bentuk persentase, maka data FDI akan diubah ke dalam rumus sebagai berikut:

FDI triwulan sekarang - FDI triwulan sebelumnya $\mathrm{x}$ 100\%

FDI triwulan sebelumnya

Tingkat Ekspor mengindikasikan keseluruhan nilai barang dan jasa yang berhasil dijual ke luar negeri. Oleh karena itu, data tingkat ekspor dapat dalam bentuk nominal. Data tingkat ekspor dapat diambil langsung melalui website CEIC data. Dengan demikian, proksi data ekspor pada penelitian ini akan disamakan proksinya dalam bentuk persentase. Data tingkat ekspor akan diubah ke dalam rumus sebagai berikut:

Ekspor sekarang - ekspor sebelumnya x $100 \%$

ekspor sebelumnya

Penelitian ini akan mengolah datanya dengan berdasarkan data sekunder sehingga tidak memerlukan uji validitas dan reliabilitas yang dibutuhkan ketika data dalam bentuk kuesioner (primer). Dengan demikian, instrumen-instrumen yang akan diuji telah dibuktikan keabsahannya oleh sumber-sumber kredibel yang telah mempublikasikannya. 
Alat analisis yang digunakan pada penelitian ini yaitu dengan menggunakan uji VAR atau VECM. Uji stasioneritas perlu dilakukan terlebih dahulu untuk menunjukkan data memiliki akar unit atau tidak. Data yang memiliki akar-akar unit akan menciptakan regresi lancung (Widarjono, 2013). Regresi lancung akan membuat suatu regresi menjadi bias karena secara statistik regresi tersebut sebenarnya tidak signifikan.

Jika data pada semua variabel masih ada yang tidak stasioner atau masih memiliki akar unit, maka uji kointegrasi dapat dilakukan. Uji VAR digunakan jika data yang digunakan telah stasioner semua dan bebas dari kointegrasi. Namun sebaliknya uji VECM akan digunakan jika data masih belum ada yang stasioner tetapi sudah saling terkointegrasi (Sihombing \& Sundoro, 2017).

Model persamaan regresi dalam VECM yang dapat dituliskan dalam penelitian ini adalah sebagai berikut:

$$
\begin{aligned}
& P D B_{t}=a_{1}+\sum_{i=1}^{P} b_{1 i} P D B_{t-i}+\sum_{i=1}^{P} e_{1 i} E X P_{t-i}+\sum_{i=1}^{P} f_{1 i} F D I_{t-i}+u_{1 t} \\
& E X P_{t}=a_{1}+\sum_{i=1}^{P} b_{1 i} E X P_{t-i}+\sum_{i=1}^{P} e_{1 i} P D B_{t-i}+\sum_{i=1}^{P} f_{1 i} F D I_{t-i}+u_{1 t} \\
& F D I_{t}=a_{1}+\sum_{i=1}^{P} b_{1 i} F D I_{t-i}+\sum_{i=1}^{P} e_{1 i} P D B_{t-i}+\sum_{i=1}^{P} f_{1 i} E X P_{t-i}+u_{1 t}
\end{aligned}
$$

\section{HASIL DAN PEMBAHASAN}

Langkah pertama dalam pemodelan VECM adalah melakukan uji akar unit. Penelitian ini akan menggunakan uji akar unit Augmented Dickey Fuller (ADF). Uji ini diperlukan untuk mengetahui apakah ada atau tidaknya akar unit pada tingkat level. Pengujian stasioneritas kembali dilakukan dalam kondisi 
pembedaan pertama (first difference) jika pada tingkat level masih mengandung akar unit. Hasil uji stasioneritas pada penelitian ini dapat terlihat pada Tabel 4.

Tabel 4.

Hasil Uji Stasioneritas

\begin{tabular}{lllll}
\hline \multirow{2}{*}{ Variabel } & \multicolumn{2}{c}{ Level } & \multicolumn{2}{c}{ First Difference } \\
\cline { 2 - 5 } & P-value & Keterangan & P-value & Keterangan \\
\hline PDB & 0,4173 & Tidak Stasioner & 0,0000 & Stasioner \\
FDI & 0,0000 & Stasioner & 0,0000 & Stasioner \\
EXP & 0,0000 & Stasioner & 0,0000 & Stasioner \\
\hline
\end{tabular}

Sumber: E-views, data diolah 2020

Berdasarkan Tabel 4 dapat diketahui bahwa masih ada variabel yang memiliki akar unit pada tingkat level. Pada tingkat turunan pertama (first difference), semua data variabel telah bebas dari akar unit seperti yang terlihat bahwa $P$-value sebesar 0.000 . Berhubung semua data variabel pada penelitian ini baru terbebas dari akar unit pada tingkat first difference, maka adanya kemungkinan apakah semua data variabel di penelitian ini tetap memiliki keterkaitan dalam jangka panjang (Juanda dan Junaidi, 2012). Oleh karena itu, uji kointergrasi akan dilakukan pada penelitian ini seperti yang terlihat pada Tabel 5.

Tabel 5.

\section{Hasil Uji Kointegrasi}

\begin{tabular}{ccccc}
\hline $\begin{array}{c}\text { Hypothesized } \\
\text { No. of CE(s) }\end{array}$ & Eigenvalue & Statistic & Critical Value & Prob.** \\
\hline None * & 0.528467 & 47.84784 & 29.79707 & 0.0002 \\
At most 1 * & 0.374450 & 19.28071 & 15.49471 & 0.0128 \\
At most 2 & 0.037540 & 1.454002 & 3.841466 & 0.2279 \\
\hline Sumber: E-views, data diolah 2020 & & &
\end{tabular}


Dari hasil uji kointegrasi pada Tabel 5 dapat dilihat bahwa adanya 2 persamaan kointegrasi yang memiliki nilai Prob. di bawah 0.05. Oleh karena itu dalam jangka panjang sudah pasti adanya keterkaitan dari semua variabel pada penelitian ini. Selanjutnya uji dengan metode VECM yang lebih cocok digunakan pada penelitian ini. Pembahasan dengan analisis VECM memerlukan bantuan analisis Impulse Response Function (IRF). Hasil IRF pada penelitian ini dapat dilihat pada Tabel 6 .

Tabel 6.

Hasil Impulse Response Function (IRF)

\begin{tabular}{lllllllll}
\hline \hline $\begin{array}{l}\text { Response of } \\
\text { GPDB: }\end{array}$ & GFDI & GEXP & $\begin{array}{l}\text { Response of } \\
\text { Period }\end{array}$ & \multicolumn{7}{c}{$\begin{array}{l}\text { GFDI: } \\
\text { Period }\end{array}$} & & & & $\begin{array}{l}\text { GPDB } \\
\text { GEXP: } \\
\text { Period }\end{array}$ & GEXP & $\begin{array}{l}\text { Response of } \\
\text { GPDB }\end{array}$ & GFDI \\
\hline \hline 1 & 0.000000 & 0.000000 & 1 & -2.439177 & 0.000000 & 1 & 6.180649 & -4.744360 \\
2 & -0.022968 & 0.029921 & 2 & 0.023587 & -2.626669 & 2 & -0.557338 & -4.501453 \\
3 & 0.002071 & -0.001651 & 3 & -1.019789 & -2.459450 & 3 & 5.496639 & -6.580347 \\
4 & -0.017310 & 0.021878 & 4 & -0.638891 & -1.676650 & 4 & 1.251480 & -4.614072 \\
5 & -0.004958 & 0.007206 & 5 & -0.895235 & -2.009036 & 5 & 3.583881 & -5.230330 \\
6 & -0.011666 & 0.015151 & 6 & -0.712558 & -2.084753 & 6 & 2.552339 & -5.398639 \\
7 & -0.008591 & 0.011498 & 7 & -0.789364 & -1.971342 & 7 & 2.912555 & -5.144435 \\
8 & -0.009675 & 0.012768 & 8 & -0.784433 & -2.008316 & 8 & 2.847823 & -5.285758 \\
9 & -0.009526 & 0.012622 & 9 & -0.767288 & -2.005248 & 9 & 2.797500 & -5.210628 \\
10 & -0.009327 & 0.012360 & 10 & -0.782672 & -2.009674 & 10 & 2.877090 & -5.262803 \\
11 & -0.009590 & 0.012686 & 11 & -0.772511 & -2.002577 & 11 & 2.807779 & -5.228708 \\
12 & -0.009375 & 0.012425 & 12 & -0.779111 & -2.006650 & 12 & 2.854677 & -5.244613 \\
\hline \hline
\end{tabular}

Sumber: E-views, data diolah 2020

Hasil uji IRF pada Tabel 6 dapat menjawab bagaimana hubungan di antara variabel PDB, FDI dan tingkat ekspor selama terjadinya era perang dagang global. Dalam jangka pendek, PDB akan merespon secara negatif terhadap perubahan yang terjadi pada investasi asing (FDI) mulai dari periode ke-1 sampai ke-7. Mulai periode ke- 8 sampai seterusnya, PDB akan kembali ke titik stabil setelah adanya perubahan pada FDI dengan respon di jangka panjang yang sama negatif 
pula yaitu sebesar -0.009. FDI juga akan merespon secara negatif terhadap perubahan yang terjadi pada PDB dalam jangka pendek yang dimulai dari periode ke-1 sampai dengan ke-10. Namun mulai periode ke-11 sampai dengan seterusnya, respon FDI terhadap PDB sudah mulai konstan yaitu sebesar -0.77 . Dengan demikian, dalam jangka panjang FDI juga akan merespon secara negatif terhadap perubahan yang terjadi pada PDB. Beberapa temuan yang dilakukan oleh Akinlo (2004), Alaya (2006) dan Marc (2011), menyatakan bahwa hubungan yang terjadi di antara FDI dengan PDB dapat berlangsung secara negatif.

Hubungan jangka pendek dan jangka panjang di antara PDB dengan tingkat ekspor yang terjadi di Indonesia selama era perang dagang global juga dapat dilihat pada Tabel 6. Dalam jangka pendek walaupun hanya pada periode ke 3 PDB merespon secara negatif terhadap tingkat ekspor, namun selanjutnya PDB pada Indonesia akan lebih merespon secara positif terhadap perubahan yang terjadi pada tingkat ekspor. Selanjutnya mulai periode ke-8 sampai selanjutnya, PDB akan lebih merespon secara positif terhadap tingkat ekspor dengan kisaran 0.012 yang artinya dalam jangka panjang jika ada perubahan pada tingkat ekspor sebesar 1\% maka PDB akan merespon secara positif sebesar $0.012 \%$. Begitu juga respon tingkat ekspor terhadap PDB dalam jangka pendek maupun jangka panjang juga akan merespon secara positif. Banyak temuan yang menyatakan bahwa dengan semakin besarnya tingkat ekspor maka PDB sebuah negara juga akan turut naik (Vardari, 2015; mau pun Raza \& Ying, 2017).

Hubungan di antara FDI dan tingkat ekspor saling merespon secara negatif. Dalam jangka pendek dari periode ke-1 sampai dengan ke-7, FDI akan 
merespon secara negatif terhadap perubahan yang terjadi pada tingkat ekspor. Sampai akhirnya FDI akan kembali ke titik keseimbangan di jangka panjang yang dimulai pada periode ke-8 sampai seterusnya dengan respon di kisaran -2.00. Begitu pula dalam jangka pendek, ekspor akan merespon secara negatif terhadap perubahan yang terjadi pada FDI dimulai dari periode ke-1 sampai dengan ke-7. Dalam jangka panjang ekspor akan merespon FDI secara negatif dengan kisaran 5.2. Temuan ini sesuai dengan penelitian yang dilakukan oleh Blonigen (2005). Temuannya menyatakan bahwa FDI yang dilakukan oleh Jepang ke Indonesia selama periode pengamatannya merupakan horizontal FDI. Jepang menanamkan modalnya di Indonesia dengan tujuan untuk merubah input ke barang jadi yang kemudian dijual kembali di pasar domestik Indonesia. Dengan demikian, ekspor Indonesia ke Jepang juga akan turun.

\section{SIMPULAN DAN SARAN}

Pemerintah Indonesia harus berhati-hati terhadap kondisi perang global karena tingkat ekspor dan PDB akan berjalan searah. Dengan demikian ketika kondisi perang dagang gobal semakin meluas, maka hal yang paling diprihatinkan adalah terjadinya penurunan kegiatan ekspor yang nantinya akan berimbas kepada tingkat PDB. FDI yang terjadi di Indonesia lebih banyak investasi asing yang bersifat horizontal. FDI horizontal dapat memungkinkan perusahaan multinasional akan berinvestasi di suatu negara dengan mendirikan anak cabang dengan tujuan tidak hanya menghemat biaya tetapi juga untuk mendekati konsumen. Hasil dari FDI yang dilakukan oleh investor asing lebih banyak digunakan untuk dijual 
kembali di pasar domestik Indonesia. Dengan demikian ketika terjadinya peningkatan FDI seperti ini, maka kegiatan ekspor bahan baku maupun barang jadi dari Indonesia akan semakin berkurang.

Kekhawatiran utama dari adanya perang dagang global yaitu terjadinya resesi global yang ditandai dari adanya penurunan kegiatan ekspor dari beberapa negara. Pemerintah sudah harus memperhatikan kebijakan-kebijakan yang harus diambil supaya kegiatan ekspor tetap tinggi yang nantinya dapat menunjang PDB Indonesia. Salah satu kebijakannya yaitu dengan mengupayakan FDI yang bersifat vertikal. Pemerintah harus membuat kebijakan yang mudah supaya investor asing dapat masuk ke Indonesia dengan menanamkan modalnya di sini. Selain itu, Pemerintah perlu mengupayakan agar kegiatan investasi asing tersebut lebih ditujukan dalam keperluan menghemat biaya produksi saja bukan untuk keperluan lainnya seperti market sharing. FDI yang bersifat vertikal akan membuat Indonesia nantinya akan melakukan kegiatan ekspor berupa barang jadi karena sebelumnya investor asing telah berinvetasi terlebih dahulu dalam rangka menghemat biaya bahan baku.

\section{REFERENSI}

Akinlo, A. (2004). Foreign Direct Investment and Growth in Nigeria: An Empirical Investigation. Journal of Policy Modeling, (26), 627-639.

Alaya, M. (2006). Investissement direct étranger et croissance économique: une estimation à partir d'un modèle structurel pour les pays de la rive sud de la Méditerranée. LES Cahiers de L'IRD, Paris, AUF.

Blonigen, B. A. (2005). A Review of the Empirical Literature on FDI Determinants. Atlantic Economic Journal, (33), 383-403. https://doi.org/10.1007/s11293-005-2868-9 
Carvalho, M., Azevedo, A., \& Massuquetti, A. (2019). Emerging Countries and the Effects of the Trade War between US and China. Economies, Vol 7, No 45 .

Eryigit, M. (2012). The Long Run Relationship between Foreign Direct Investments, Exports, and Gross Domestic Product: Panel Data Implications. Theoretical and Applied Economics, Volume XIX, No. 10 (575), pp. 71-82.

Juanda, B., \& Junaidi. (2012). Ekonometrika Deret Waktu: Teori dan Aplikasi. Bogor: IPB press.

Mandal, K. (2012). Foreign Direct Investment and Economic Growth: An Analysis for Selected Asian Countries. Journal of Business, 4 (1), 15-24.

Marc, A. (2011). Is Foreign Direct Investment A Cure for Economic Growth in Developing Countries? Structural Model Estimation Applied to the Case of the South Shore Mediterranean Countries. Journal of International Business and Economics, 11 (4).

Oladipo, O. S. (2013). Does Foreign Direct Investment Cause Long Run Economic Growth? Evidence from the Latin American and the Caribbean countries. International Economics and Economic Policy 10 (4), 569-582. http://dx.doi.org/10.1007/s1036801202254.

Petrevski, G., \& Jovanovski, K. (2017). The Global Financial and Economic Crisis: Its Impact on Macedonia. Conference: International Conference on Economic Policy and Global Recession, At University of Belgrade, Faculty of Economics, Belgrade, Serbia., Volume: 1.

Rahman, M. M., \& Shahbaz, M. (2013). Do Imports and Foreign Capital Inflows Lead Economic Growth? Cointegration and Causality Analysis in Pakistan. South Asia Economic Journal, 14 (1), 59-81. http://dx.doi.org/10.1177/1391561413477941.

Raza, M., \& Ying, Z. X. (2017). The Causal Relationship between Export and Economic Growth of Pakistan. International Journal of Economics, Commerce and Management, Vol. V, Issue 2, ISSN 23480386.

Sihombing, P., dan Sundoro, H. S. (2017). Pengaruh Faktor Makroekonomi dan Likuiditas terhadap Yield Curve Obligasi Pemerintah Indonesia. Media Ekonomi Vol 25, No 2. DOI: http://dx.doi.org/10.25105/me.v25i2.4894

Steinbock, D. (2018). U.S-China Trade War and Its Global Impacts. China Quarterly of International Strategic Studies, Vol 4, No 4.

Suyanto, B. H., Bloch, H., \& Salim, R. A. (2012). Foreign Direct Investment Spillovers and Productivity Growth in Indonesian Garment and Electronics Manufacturing". The Journal of Development Studies, 48 (10), 1397-1411. http://dx.doi.org/10.1080/00220388.2011.646992

Tekin, R. B. (2012). Economic Growth, Exports, and Foreign Direct Investment in Least Developed Countries: A Panel Granger Causality Analysis. Economic Modeling, (29), 868-878. http://dx.doi.org/ 10.1016/j.econmod.

Vardari, L. (2015). Relationship between Import-Exports and Economic Growth: The Kosova Case Study. Reforma, 34 (05): Pp 262-269. 
Hary Saputra Sundoro. Hubungan Jangka Pendek dan Jangka Panjang di antara FDI.

Viju, C., Yeung, M.T., \& Kerr. W. A. (2011). Post-Moratorium EU Regulation of Genetically Modified Products: Triffid Flax. Canadian Agricultural Trade Policy and Competitiveness Research Network, September 2011.

Widarjono, A. (2013). Ekonometrika Pengantar dan Aplikasinya. Jakarta: Ekonosia. 